\title{
Real-World Treatment Patterns Among Patients Initiating Small Molecule Kinase Inhibitor Therapies for Thyroid Cancer in the United States
}

\author{
Stacey A. Dacosta Byfield · Oluwakayode Adejoro · Ronda Copher • \\ Debanjana Chatterjee · Prashant R. Joshi · Francis P. Worden
}

Received: November 13, 2018 / Published online: February 28, 2019

(C) The Author(s) 2019

\begin{abstract}
Introduction: Little is known about real-world use of small molecule kinase inhibitors (SMKI) for advanced thyroid cancer in the United States. This study examined prescribing patterns of SMKI agents recommended by the National Comprehensive Cancer Center (NCCN).

Methods: This retrospective study used a national health insurance database to identify patients diagnosed with thyroid cancer during $1 / 1 / 2006-6 / 30 / 2016$ and with prescription claims for NCCN-recommended SMKI during $1 / 1 / 2010-5 / 31 / 2016$ whose first claim date was the index date. Inclusion also required
\end{abstract}

Enhanced Digital Features To view enhanced digital features for this article go to https://doi.org/10.6084/ m9.figshare.7594565.

S. A. Dacosta Byfield ( $\square)$

Health Economics and Outcomes Research, Optum, Inc., Eden Prairie, MN, USA

e-mail: Stacey.DacostaByfield@optum.com

O. Adejoro · R. Copher - D. Chatterjee

Health Economics \& Outcomes Research, Eisai Inc., Woodcliff Lake, NJ, USA

P. R. Joshi

Oncology Medical Affairs, Eisai Inc., Woodcliff Lake, NJ, USA

F. P. Worden

Division of Medical Oncology, Department of Internal Medicine, University of Michigan, Ann Arbor, MI, USA continuous enrollment in a health plan for 3 months pre-index (baseline) and $\geq 1$ month post-index (follow-up) with no claims for SMKI during baseline. Lines of therapy (LOT) were defined by the date of SMKI claims and days of drug supply. Median time to SMKI discontinuation in each LOT was estimated by Kaplan-Meier method.

Results: The study included 217 patients. During follow-up (mean duration 499.0 days), $35.5 \%$ of patients $(n=77)$ received a second or later LOT; among patients with $\geq 12$ months follow-up after first LOT (LOT1) initiation, $53.1 \%(n=60)$ received a second or later LOT. Median treatment duration was 5.0 months for LOT1 and 5.1 months for LOT2. Over the entire follow-up period (2010-2016), sorafenib was the most common regimen in LOT1 $(36.9 \%$ of patients) and LOT2 (24.7\%) followed by sunitinib and levantinib (13.4\% each) in LOT1 and sunitinib (19.5\%) in LOT2. Starting in 2015, the year lenvatinib was approved for differentiated thyroid cancer, lenvatinib was the most common first-line regimen among patients initiating LOT1 in 2015 (43.4\%) and 2016 (66.7\%).

Conclusion: Sorafenib was the most common first-line agent during 2010-2014 but was supplanted by lenvatinib starting in 2015 . Approximately $36-53 \%$ of patients received a second-line treatment. Median treatment duration results suggested potential benefit of SMKI in second-line therapy. SMKI treatment after 
first-line failure may be considered for appropriately selected patients.

Funding: Eisai, Inc. (Woodcliff Lake, NJ).

Keywords: Lenvatinib; Sorafenib; Thyroid cancer treatment; Treatment duration

\section{INTRODUCTION}

Thyroid cancer currently accounts for $3.1 \%$ of all new cancer cases in the US but is projected to be the fourth most common cancer in the nation by $2030[1,2]$. The annual incidence has been steadily rising over the last four decades. There was an approximately $4 \%$ annual increase during 2005-2014 which has been attributed in part to improved detection of subclinical, indolent cancers [2-4]. However, this short term rise is also consistent with the long term annual increase of 3\% observed during 1974-2013 [5].

Thyroid cancers are classified by three main histological types, differentiated thyroid cancer (DTC)—which includes papillary, follicular, Hürthle cell and poorly differentiated carcinomas-medullary thyroid cancer (MTC) and anaplastic thyroid cancer. Among patients diagnosed with thyroid carcinoma during 2010-2014, DTC was by far the most common, accounting for $96 \%$ of all diagnoses [6]. Approximately $93 \%$ of DTC cases were papillary, $5 \%$ were follicular and $2 \%$ were Hürthle cell; poorly differentiated carcinomas were the least common but were not well quantified [6]. Medullary and anaplastic carcinomas represented $1.7 \%$ and $0.8 \%$ of all thyroid cancer diagnoses, respectively [6]. Anaplastic carcinoma is the most aggressive thyroid cancer with mortality approaching 100\% [7]. Although most patients with DTC and MTC can be cured by thyroidectomy, particularly when diagnosed at early stages, some DTC cases may also be managed with post-surgical radioiodine ablation (RAI) therapy $[2,8,9]$. Prognosis is altered dramatically with the development of metastatic disease [6]. The 10-year survival for DTC and MTC cases with distant metastases is $40-42 \%[10,11]$. Among DTC patients who are radioiodine refractory, 10-year survival declines to $10 \%$ with a median survival of $3-4$ years
$[10,12]$. Until recently, treatment options for advanced DTC and MTC have been limited since conventional chemotherapy is largely ineffective in controlling disease progression [9].

Advances in the understanding of the molecular pathogenesis of thyroid cancer have led to the development of targeted agents aimed at combating advanced disease. Small molecule kinase inhibitors (SMKIs) modulate cell signaling pathways responsible for tumor cell growth and proliferation $[13,14]$. The National Comprehensive Cancer Network (NCCN) and American Thyroid Association favor the use of SMKIs for management of radioiodine refractory metastatic DTC and progressive or symptomatic MTC [9, 15]. The US Food and Drug Administration (FDA) approved sorafenib (in 2013) [16] and lenvatinib (in 2015) [17] for treatment of locally recurrent or metastatic, progressive DTC refractory to RAI. The NCCN recommends consideration of lenvatinib (preferred) or sorafenib for progressive and/or symptomatic disease with selection individualized for each patient according to the likelihood of response and comorbid conditions [9]. Vandetanib (in 2011) [18] and cabozantinib (in 2012) [19] are FDA-approved for progressive, metastatic or unresectable MTC. Both are NCCN-recommended in the setting of symptomatic disease or progression [9]. Both are indicated as first-line therapy and there are no data indicating which SMKI should be considered first, hence leaving the decision to the discretion of the provider. Often MTC patients will receive both agents during the course of their disease. Other commercially available SMKIs may be considered for DTC and MTC if clinical trials are not an option for a patient [9] and are used off-label in clinical practice [20].

The current literature on SMKI treatment patterns shows extensive use of these agents in the first-line setting among patients with advanced DTC and MTC [20-23]. Further, studies that examined progression-free survival among patients treated with SMKIs in both the first- and second-line setting found evidence of clinical benefit in the second-line setting, suggesting that SMKI should be considered after first-line failure [20, 22-24]. While previous 
research has provided important insight into the use and efficacy of SMKIs beyond the clinical trial setting, studies to date were conducted prior to the commercial availability of lenvatinib in 2015 and most were single site investigations [20-23]. The overall aim of this study is to provide a more contemporary assessment of SMKI treatment patterns in the US with a broader representation of patients. To this end, a national administrative claims database was used to examine real-world prescribing patterns among patients who initiated any NCCN-recommended SMKI therapy for advanced thyroid cancer during 2010-2016. In this analysis, we examined SMKI regimens used in the first-, second- and third-line of therapy and duration of each line of therapy.

\section{METHODS}

\section{Study Design and Data Sources}

This was a retrospective, observational study using administrative claims data from the Optum Research Database (ORD) during 2010-2016. The ORD contains medical and pharmacy claims (submitted for reimbursement) and enrollment information data from a large US health insurer that provides private commercial insurance to employers and individuals as well as Medicare Advantage insurance with Part D prescription drug coverage to Medicare-eligible individuals. In 2015, the database represented approximately 13.5 million individuals with both medical and pharmacy benefit coverage under commercial or Medicare Advantage plans. According to estimates from the US Census Bureau, $89.6 \%$ of US residents had health insurance coverage in 2014 [25]. Of these, $66.0 \%(208,600,000)$ had private health insurance coverage and $36.5 \%$ had government coverage such as Medicare, Medicaid or military health care (the 2 categories were not entirely mutually exclusive). Thus, based on census estimates, the ORD sample of patients with both medical and pharmacy benefit coverage represented roughly $7 \%$ of patients with private insurance coverage in the US. The database includes medical claims for inpatient and outpatient services with International Classification of Diseases, Ninth Revision, Clinical Modification (ICD-9-CM) and International Classification of Diseases, Tenth Revision, Clinical Modification (ICD-10-CM) diagnosis and procedure codes, Current Procedural Terminology Version 4 (CPT-4) procedure codes, Healthcare Common Procedure Coding System (HCPCS) codes and place of service codes. Outpatient pharmacy claims include National Drug Codes for dispensed medications, quantity dispensed, dose and number of days' supply. The date of death (month/year) for patients who died during the study was determined from the Social Security Administration master death file.

Because no identifiable protected health information was extracted or accessed during the course of the study, and all data were accessed in compliance with the Health Insurance Portability and Accountability Act's rules, Institutional Review Board approval or waiver of authorization was not required.

\section{Patient Selection}

Patients with evidence of thyroid cancer and pharmacy claims for SMKIs were selected for inclusion in the study in a stepwise manner. First, evidence of thyroid cancer was ascertained by $\geq 2$ non-diagnostic medical claims for thyroid cancer (ICD-9-CM code 193; ICD-10-CM code C73) in any position at least 30 days apart during January 1, 2006 through June 30, 2016. Diagnostic medical claims were not considered as these may reflect a rule-out. Tumor histology was not ascertained because these data were not available. Second, $\geq 1$ pharmacy claim for NCCN-recommended SMKIs during January 1, 2010 through May 31, 2016 was required. The date of the first claim was the index date; NCCN-recommended SMKIs were axitinib, cabozantinib, everolimus, lenvatinib, pazopanib, sorafenib, sunitinib and vandetanib [9]. Third, patients were at least 18 years of age as of the index date. Fourth, continuous enrollment in the health plan with both medical and pharmacy benefits was required for at least 3 months prior to the index date (baseline period) and at least 1 month following the index 
date (follow-up period). Lastly, patients were also required to have no claims for NCCN-recommended SMKIs during the 3-month baseline period.

\section{Measures}

Baseline characteristics were determined during the 3-month pre-index period and examined by SMKI regimen cohort received during the first line of therapy (LOT). Age (as of the index date), gender and type of health insurance plan were determined from health plan enrollment information. The Quan-Charlson comorbidity score [26], top 3 individual non-cancer comorbidities (as defined by the Agency for Healthcare Research and Quality [27]) and prescribing physician specialty were determined from medical or pharmacy claims.

During follow-up, prescribing patterns and duration of treatment were examined by LOT using an established algorithm to define LOT $[28,29]$. The first LOT (LOT1) began on the index date, which was the date of the first prescription fill for any NCCN-recommended SMKI, and included all NCCN-recommended SMKIs received within 30 days of the index date. The first LOT ended at the earliest of: (1) addition or substitution of a new agent after the initial agent (note: discontinuation of one agent from a multi-drug regimen did not end a LOT); (2) SMKI treatment discontinuation, defined as a treatment gap of $\geq 60$ days after the prescription run-out date of all agents in the LOT; (3) death; or (4) disenrollment from the health plan or study end date (June 30, 2016). The start of the second LOT (LOT2) and subsequent LOTs was defined as the addition or substitution of a new agent after the end of LOT1. The end date criteria were the same as for LOT1. LOTs that ended due to study disenrollment or end of study period were retained and censored at the point of disenrollment or study end date, whichever first occurred. A schematic of the study design depicting sequential LOTs is shown in Fig. 1.

Patients were assigned to SMKI treatment regimen cohort based on the SMKI regimen received in each LOT. Six cohorts were

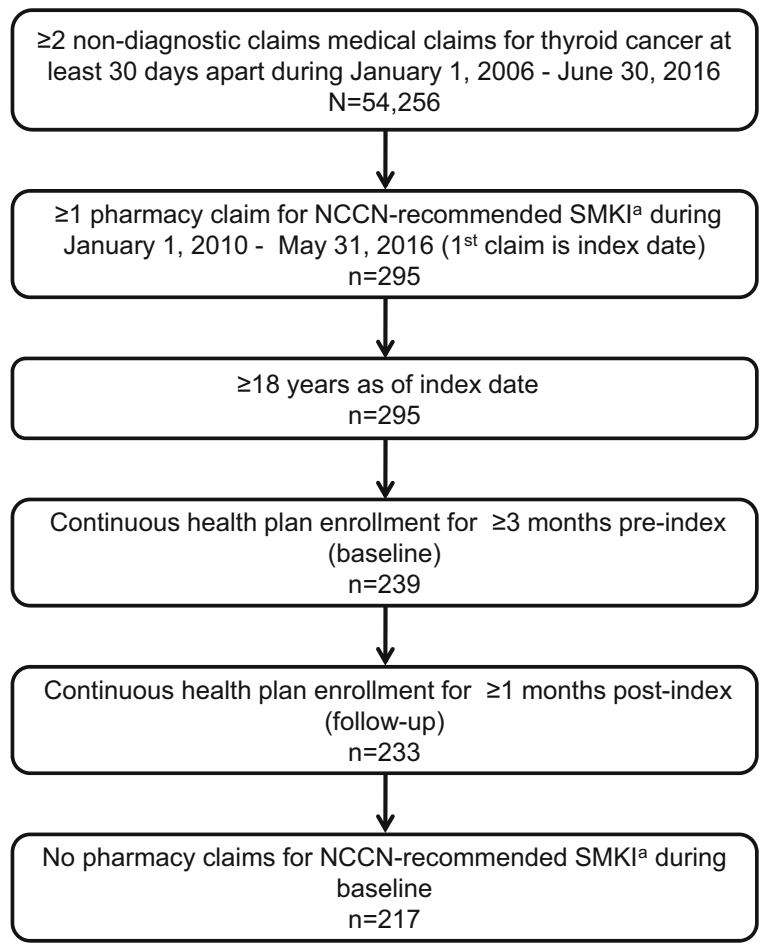

Fig. 1 Study design. LOT line of therapy, SMKI small molecule kinase inhibitor, NCCN National Comprehensive Cancer Network. 'Axitinib, cabozantinib, everolimus, lenvatinib, pazopanib, sorafenib, sunitinib and vandetanib

established: the top 5 most common SMKI regimens received in each LOT plus the "other" regimen cohort, representing all other SMKI agents/combinations of agents that were not in the top 5. The duration of each LOT was defined as the number of days in each LOT and calculated for each SMKI regimen received in LOT1, LOT2 and LOT3. In order to examine trends in treatment patterns over the duration of the study (2010-2016), the proportion of patients receiving each SMKI regimen in LOT1 and LOT2 was examined by index year (i.e., the year LOT1 was initiated). SMKI regimen transitions from LOT1 to LOT2 and LOT2 to LOT3 were also summarized. The proportion of patients with evidence of SMKI treatment receipt in LOT1, LOT2, LOT3 and LOT4 was computed for the full study sample (i.e., patients with a minimum of 1 month follow-up after the start of LOT1). Due to large differences in duration of follow-up time across cohorts, a sensitivity analysis restricted to patients with at least 12 months of 
follow-up after the start of each LOT was also conducted to minimize the impact of variable duration of follow-up on estimates of the proportion of patients receiving each LOT.

\section{Statistical Analysis}

Difference between LOT regimen cohorts for baseline characteristics, duration of follow-up and LOT duration were examined by ANOVA test for continuous variables and Chi square test for categorical variables. The time to discontinuation of each SMKI regimen in LOT1, LOT2 and LOT3 was estimated by Kaplan-Meier method to account for LOT censoring; cohort differences were assessed by log-rank test.

\section{RESULTS}

\section{Sample Selection}

The patient selection process is shown is Fig. 2 . There were 54,256 patients with at least 2 nondiagnostic medical claims for thyroid cancer during January 1, 2006-June 30, 2016. Among these patients, 295 patients had at least one pharmacy claim for NCCN-recommended SMKIs during January 1, 2010-May 31, 2016 and all were at least 18 years or older. After excluding 62 patients for lack of continuous enrollment with medical and pharmacy benefits for at least 3 month pre-index $(n=56)$ and at least 1 month post-index $(n=6)$ and an additional 16 patients with evidence of baseline use of SMKI, the final sample comprised 217 patients.

\section{Baseline Characteristics}

Baseline patient characteristics and prescribing physician specialty stratified by LOT1 regimen are shown in Table 1 . The 5 most common LOT1 regimens were all single agents: sorafenib was the most common regimen $(36.9 \%)$ followed by lenvatinib and sunitinib (13.4\% each), vandetanib (12.9\%) and pazopanib (11.1\%). "Other" regimens comprised the balance $(12.4 \%)$. Among all patients $(n=217)$, mean age was 61.2 years, $51.7 \%$ were female and the mean Quan-Charlson comorbidity score was 7.5. The mean (median) duration of follow-up was 499 (378) days. Patients who received "other" regimens and lenvatinib were the

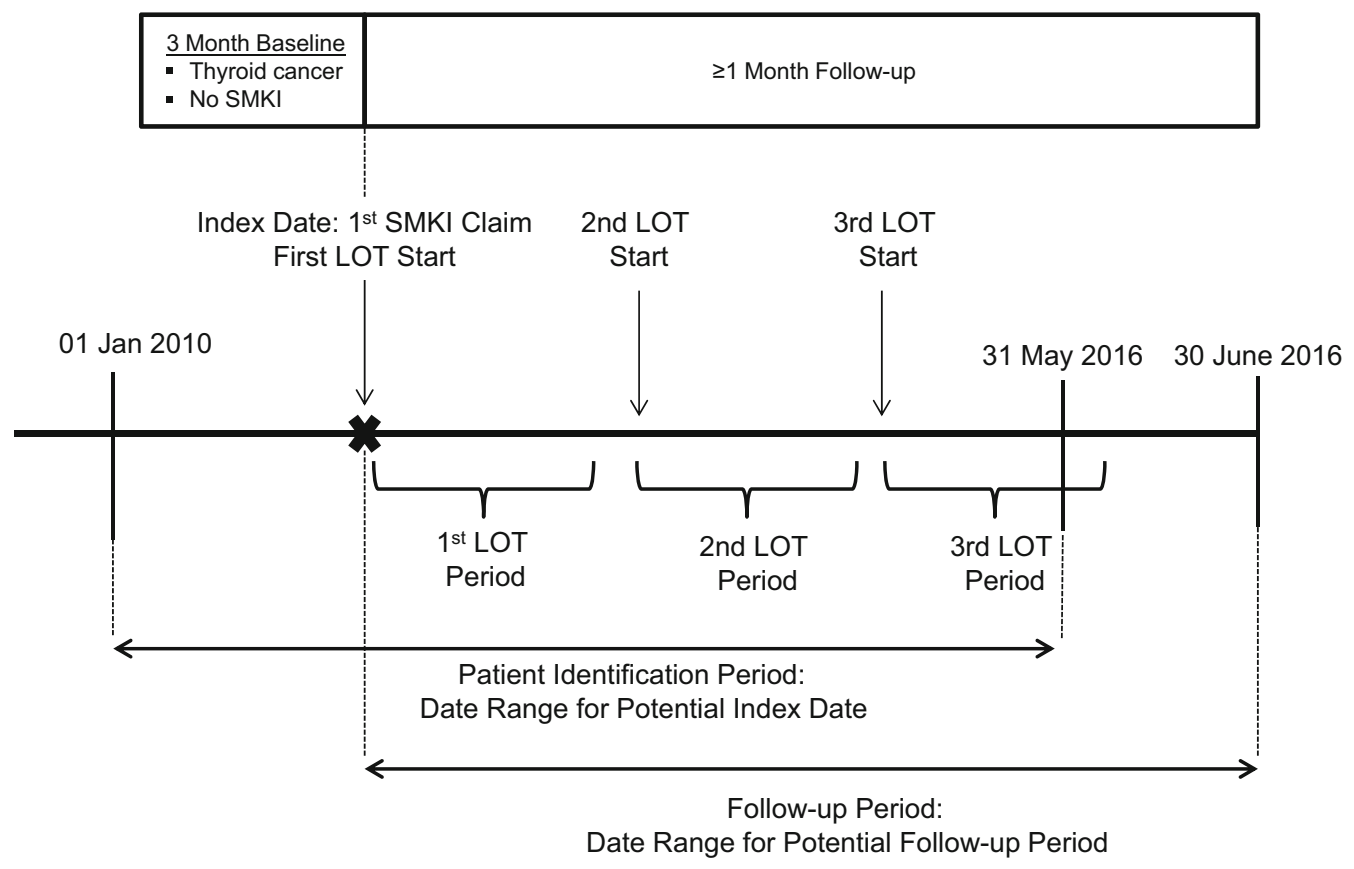

Fig. 2 Patient selection. SMKI small molecule kinase inhibitor, LOT line of therapy 
Table 1 Baseline patient characteristics and prescribing physician specialty by first LOT regimen

\begin{tabular}{|c|c|c|c|c|c|c|c|c|}
\hline \multirow[t]{2}{*}{ Characteristic } & \multicolumn{8}{|c|}{ First LOT Regimen } \\
\hline & $\begin{array}{l}\text { All } \\
(N=217)\end{array}$ & $\begin{array}{l}\text { Sorafenib } \\
(n=80)\end{array}$ & $\begin{array}{l}\text { Sunitinib } \\
(n=29)\end{array}$ & $\begin{array}{l}\text { Lenvatinib } \\
(n=29)\end{array}$ & $\begin{array}{l}\text { Vandetanib } \\
(n=28)\end{array}$ & $\begin{array}{l}\text { Pazopanib } \\
(n=24)\end{array}$ & $\begin{array}{l}\text { Other } \\
(n=27)\end{array}$ & $p$ value $^{a}$ \\
\hline $\begin{array}{l}\text { Age, mean years } \\
\text { (SD) }\end{array}$ & $\begin{array}{l}61.2 \\
(12.5)\end{array}$ & $64.0(11.1)$ & $\begin{array}{l}58.5 \\
\quad(11.0)\end{array}$ & $65.7(12.5)$ & $59.1(14.9)$ & $57.9(14.3)$ & $\begin{array}{l}56.0 \\
(11.3)\end{array}$ & 0.006 \\
\hline Female, $n(\%)$ & $112(51.6)$ & $45(56.3)$ & $11(37.9)$ & $11(37.9)$ & $14(50.0)$ & $9(37.5)$ & $\begin{array}{l}22 \\
(81.5)\end{array}$ & 0.004 \\
\hline \multicolumn{9}{|l|}{ Insurance, $n(\%)$} \\
\hline Commercial & $137(63.1)$ & $44(55.0)$ & $24(82.8)$ & $14(48.3)$ & $15(53.6)$ & $18(75.0)$ & $\begin{array}{l}22 \\
(81.5)\end{array}$ & 0.005 \\
\hline$<65$ years & $115(83.9)$ & $35(79.6)$ & $20(83.3)$ & $9(64.3)$ & $15(100.0)$ & $16(88.9)$ & $\begin{array}{l}20 \\
\quad(90.9)\end{array}$ & 0.134 \\
\hline$\geq 65$ years & $22(16.1)$ & $9(20.5)$ & $4(16.7)$ & $5(35.7)$ & $0(0)$ & $2(11.1)$ & $2(9.1)$ & 0.134 \\
\hline $\begin{array}{l}\text { Medicare } \\
\text { Advantage }\end{array}$ & $80(36.9)$ & $36(45.0)$ & $5(17.2)$ & $15(51.7)$ & $13(46.4)$ & $6(25.0)$ & $5(18.5)$ & 0.005 \\
\hline $\begin{array}{l}\text { Quan-Charlson } \\
\text { comorbidity } \\
\text { score, mean } \\
\text { (SD) }\end{array}$ & $7.5(1.8)$ & $7.4(1.8)$ & $7.6(1.4)$ & $7.5(1.4)$ & $7.6(2.0)$ & $7.8(2.3)$ & $7.7(2.2)$ & 0.957 \\
\hline \multicolumn{9}{|c|}{ Most common non-cancer comorbidities, $n(\%)$} \\
\hline Heart disease & $151(69.9)$ & $55(69.6)$ & $20(69.0)$ & $22(75.9)$ & $17(60.7)$ & $19(79.2)$ & $\begin{array}{l}18 \\
\quad(66.7)\end{array}$ & 0.752 \\
\hline $\begin{array}{l}\text { Spondylosis, } \\
\text { intervertebral } \\
\text { disc disorders, } \\
\text { other back } \\
\text { problems }\end{array}$ & $138(63.9)$ & $50(63.3)$ & $18(62.1)$ & $17(58.6)$ & $16(57.1)$ & $18(75.0)$ & $\begin{array}{l}19 \\
(70.4)\end{array}$ & 0.748 \\
\hline $\begin{array}{l}\text { Other } \\
\text { connective } \\
\text { tissue disease }\end{array}$ & $134(62.0)$ & $53(67.1)$ & $16(55.2)$ & $16(55.2)$ & $13(46.4)$ & $19(79.2)$ & $\begin{array}{l}17 \\
\quad(63.0)\end{array}$ & 0.159 \\
\hline \multicolumn{9}{|c|}{ Prescribing physician specialty, $n$ (\%) } \\
\hline Endocrinology & $52(24.0)$ & $19(23.8)$ & $3(10.3)$ & $9(31.0)$ & $7(25.0)$ & $5(20.8)$ & $9(33.3)$ & 0.365 \\
\hline Hematology & $13(6.0)$ & $6(7.5)$ & $2(6.9)$ & 0 & $1(3.6)$ & $1(4.2)$ & $3(11.1)$ & 0.591 \\
\hline $\begin{array}{l}\text { Medical } \\
\text { oncology }\end{array}$ & $34(15.7)$ & $17(21.3)$ & $5(17.2)$ & $3(10.3)$ & $5(17.9)$ & $4(16.7)$ & 0 & 0.100 \\
\hline $\begin{array}{r}\text { Radiation } \\
\text { oncology }\end{array}$ & 0 & 0 & 0 & 0 & 0 & 0 & 0 & - \\
\hline
\end{tabular}


Table 1 continued

\begin{tabular}{|c|c|c|c|c|c|c|c|c|}
\hline \multirow[t]{2}{*}{ Characteristic } & \multicolumn{8}{|c|}{ First LOT Regimen } \\
\hline & $\begin{array}{l}\text { All } \\
(N=217)\end{array}$ & $\begin{array}{l}\text { Sorafenib } \\
(n=80)\end{array}$ & $\begin{array}{l}\text { Sunitinib } \\
(n=29)\end{array}$ & $\begin{array}{l}\text { Lenvatinib } \\
(n=29)\end{array}$ & $\begin{array}{l}\text { Vandetanib } \\
(n=28)\end{array}$ & $\begin{array}{l}\text { Pazopanib } \\
(n=24)\end{array}$ & $\begin{array}{l}\text { Other } \\
(n=27)\end{array}$ & $p$ value $^{\mathrm{a}}$ \\
\hline $\begin{array}{l}\text { Surgical } \\
\text { oncology }\end{array}$ & $1(0.5)$ & 0 & 0 & 0 & 0 & $1(4.2)$ & 0 & 0.111 \\
\hline Other & $60(27.7)$ & $22(27.5)$ & $8(27.6)$ & $7(24.1)$ & $8(28.6)$ & $7(29.2)$ & $8(29.6)$ & 0.998 \\
\hline Unknown & $57(26.3)$ & $16(20.0)$ & $11(37.9)$ & $10(34.5)$ & $7(25.0)$ & $6(25.0)$ & $7(25.9)$ & 0.440 \\
\hline
\end{tabular}

All patients had $\geq 1$ month follow-up

$L O T$ line of therapy, $S D$ standard deviation

${ }^{a}$ By ANOVA for continuous variables and Chi square test for percentages

youngest (56.0 years) and oldest (65.7 years), respectively $(p=0.006)$. There was either male predominance or a similar proportion of males and females in most cohorts with the exception of "other" regimens and the sorafenib cohort where there was female predominance $(p=0.004)$. The mean Quan-Charlson comorbidity score and the percentage of patients with the top 3 non-cancer comorbidities did not differ between cohorts. Endocrinology was the most common prescribing physician specialty (24.0\% of all patients) based on the first SMKI prescription fill in LOT1; differences in prescribing physician specialty between cohorts were not observed. The large majority of prescribing physicians $(83.0 \%)$ were affiliated with a community hospital or non-academic setting (data not shown).

\section{Duration of Follow-Up and Lines of Therapy}

Following the start of the first LOT, patients were observed on average for 499.0 days (Table 2). Mean duration of follow-up time differed by LOT1 cohort $(p<0.001)$ : the lenvatinib cohort had the shortest follow-up (249 days) and the vandetanib cohort had the longest follow-up (686 days). The majority of patients had complete (i.e., uncensored) LOT data. The percentage of patients with complete LOT data vs. those with LOTS censored due to lack of continuous enrollment or end of study period was $71.4 \%$ vs. $28.6 \%$ for LOT1, $66.2 \%$ vs. $33.8 \%$ in LOT2 and $69.2 \%$ vs. $30.8 \%$ in LOT3. However, the percentage of patients with complete LOT data differed by cohort in LOT1 $(p<0.001)$ : the lenvatinib cohort had the lowest percentage of patients with complete LOT1 data $(34.5 \%)$, followed by pazopanib $(66.7 \%)$, vandetanib (75.0\%), "other" regimens (77.9\%) sunitinib (79.3\%) and sorafenib (80.0\%). Although significant differences were not observed in later LOTs $(p \geq 0.163)$, the lenvatinib cohort also consistently had the smallest percentage of patients with complete LOT data in LOT2 and LOT3 (25.0-30.0\%) compared with all other cohorts (62.5-88.9\%). These results likely reflect differences in the availability of the regimens relative to the end date for inclusion in the study (May 31, 2016). Lenvatinib was the last drug to become available following FDA approval for DTC in 2015; vandetanib (for MTC), cabozantinib (for MTC), and sorafenib (for DTC) were approved in 2011, 2012 and 2013 , respectively. In addition, three of the top 5 single agent regimens were commercially available based on FDA approval for indications other than advanced thyroid cancer before January 1, 2010, the study start date: sorafenib (2005), sunitinib (2006) and pazopanib (2009).

The percentage of patients receiving first and subsequent lines of therapy across all SMKI regimens is shown in Fig. 3. Among the full study sample $(n=217), 64.5 \%$ of all patients 


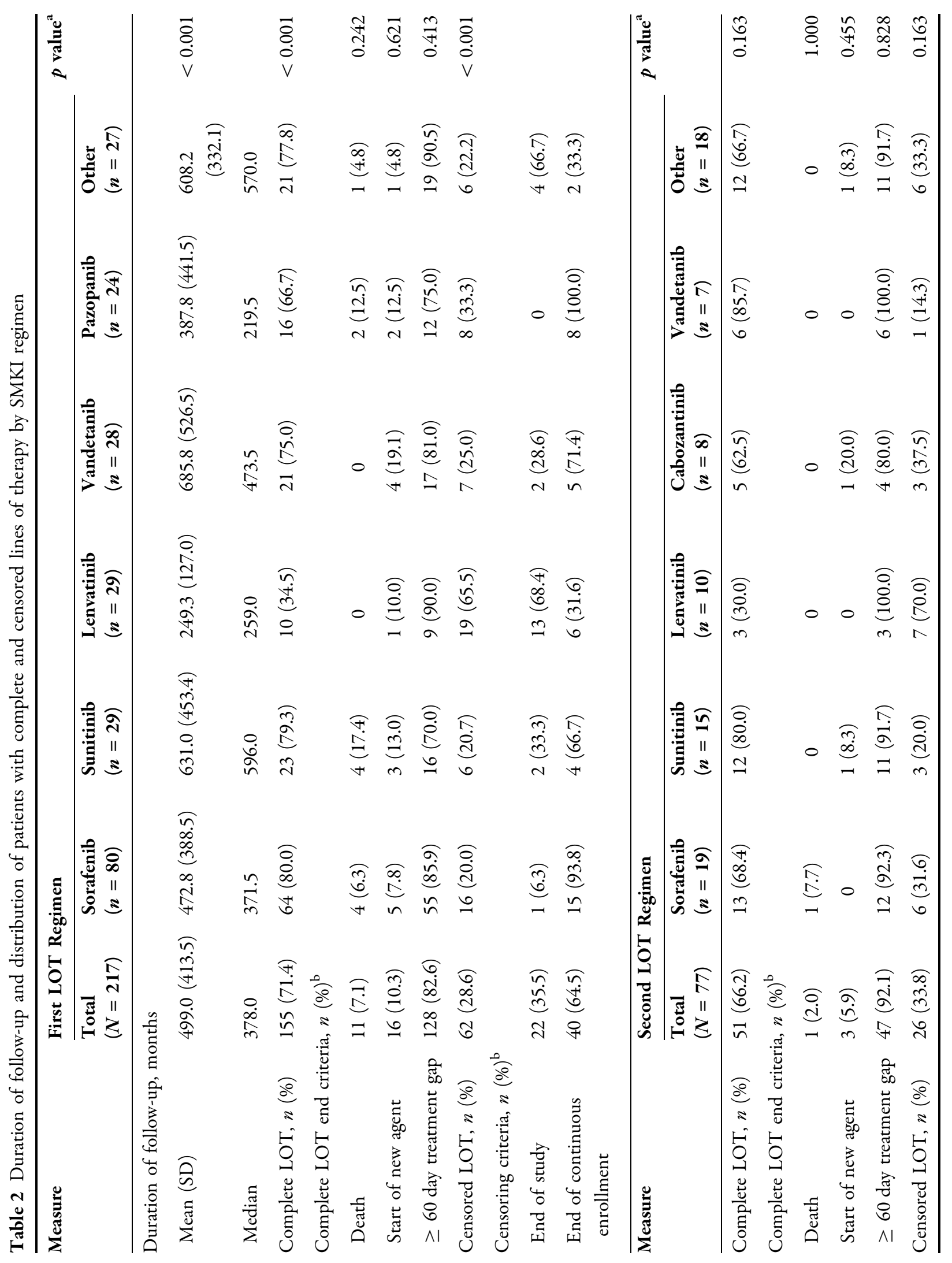




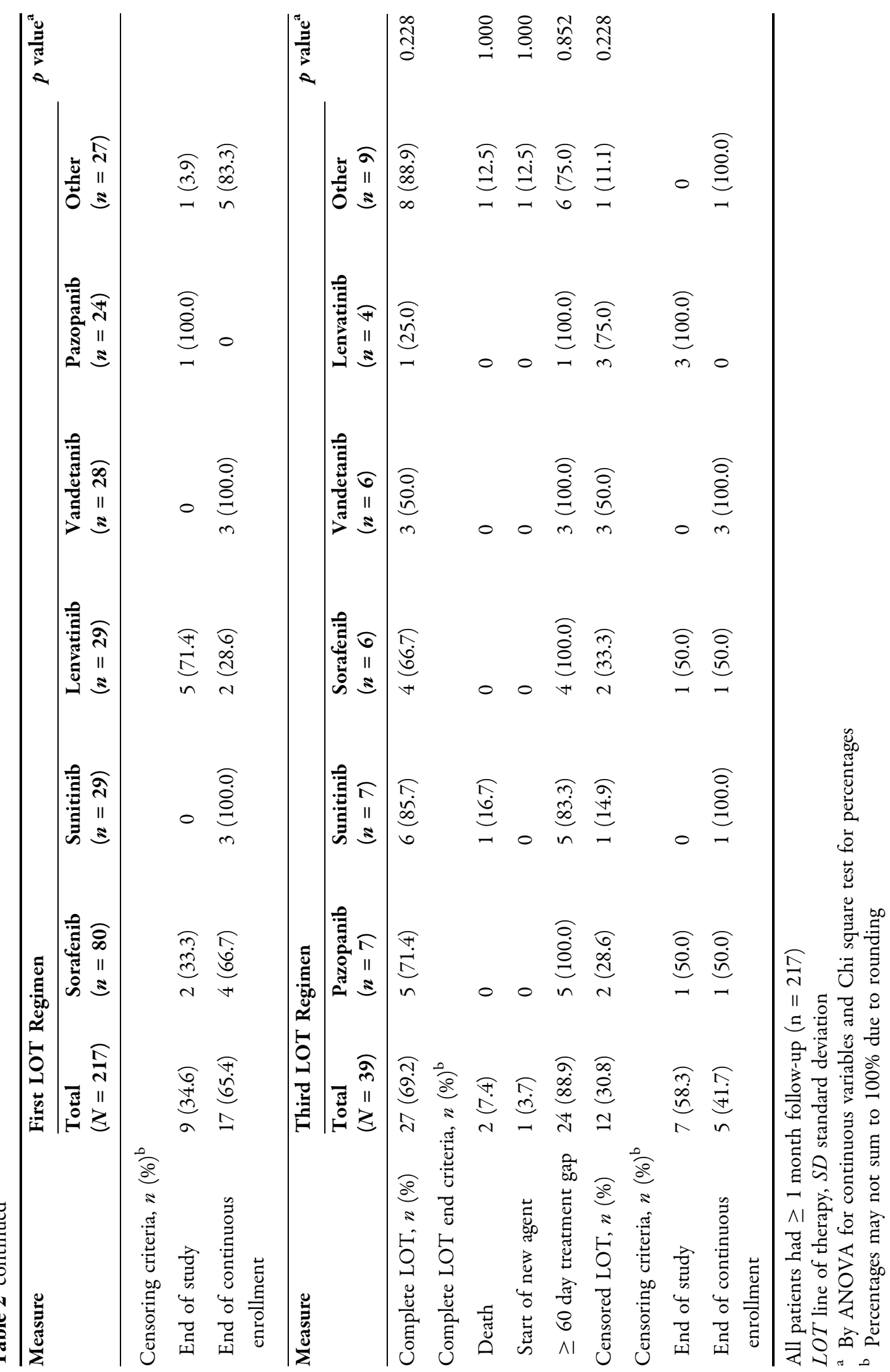



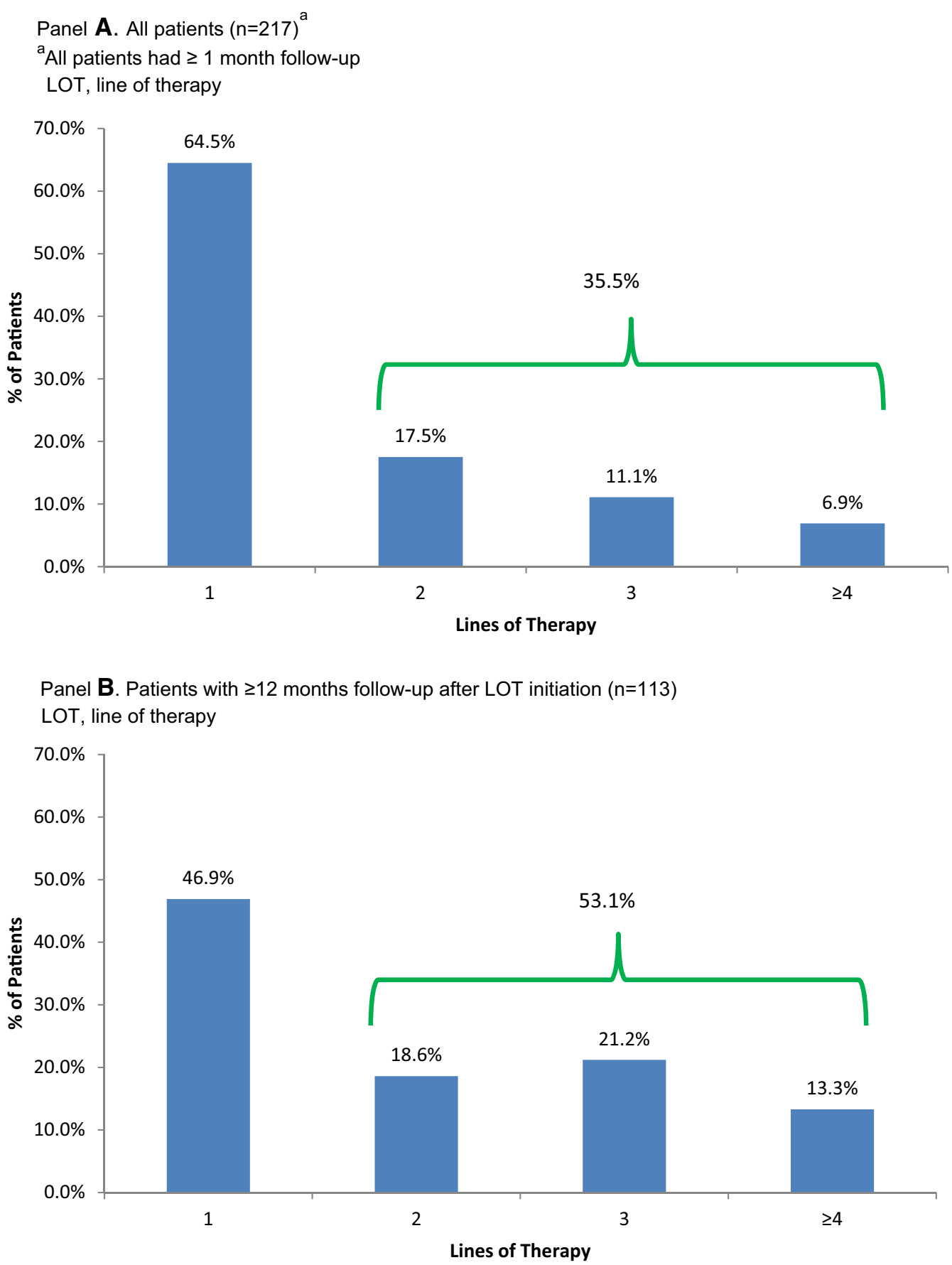

Fig. 3 Distribution of patients by line of therapy

received first-line treatment only and $35.5 \%$ of patients received a second or later LOT. In the sensitivity analysis examining patients with at least one year of follow-up from the start of LOT1 $(n=113), 53.1 \%$ of patients received SMKI treatment in a second or later LOT.

\section{SMKI Regimens by Line of Therapy}

Across all index years (2010-2016), patients most commonly received sorafenib in the firstline (36.9\%) and second-line settings (24.7\%) (Fig. 4). The second most common regimens 
Panel A. First LOT regimens $(n=217)$

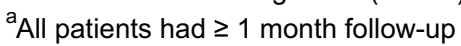

LOT, line of therapy

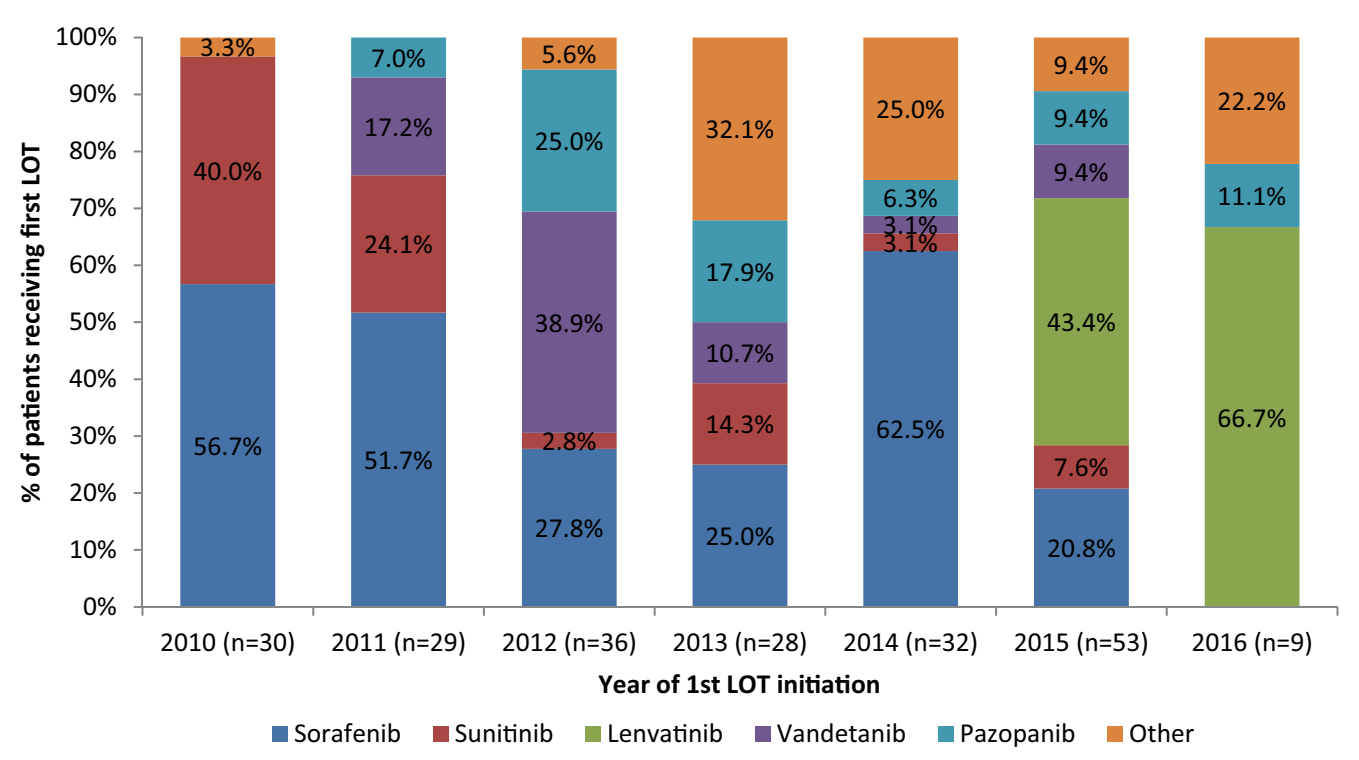

Panel B. Second LOT Regimens $(n=77)$

${ }^{a}$ All patients had $\geq 1$ month follow-up

LOT, line of therapy

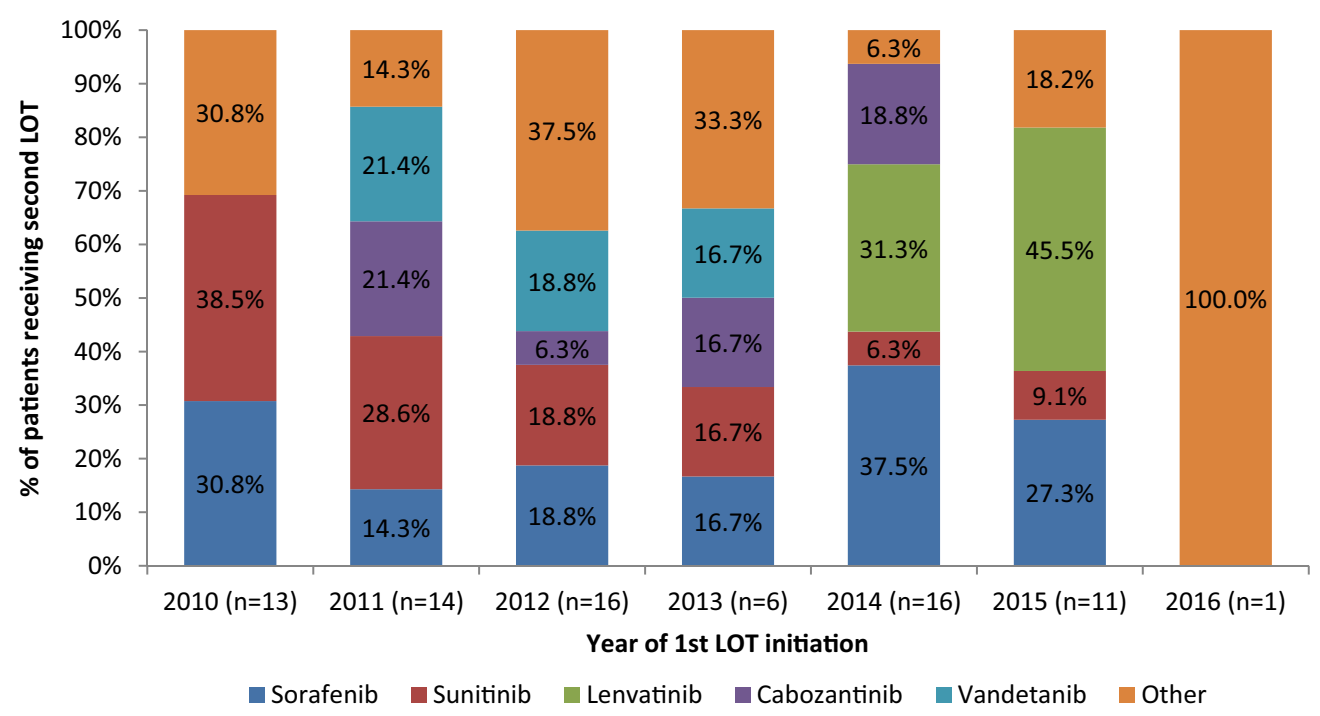

Fig. 4 SMKI regimens by year of first LOT initiation ${ }^{a}$

were sunitinib and lenvatinib in LOT1 (13.4\% each) and sunitinib in LOT2 (19.5\%). During index year 2015, the year lenvatinib became commercially available, lenvatinib became the predominant regimen in LOT1, representing
$43.4 \%$ of all patients and the pattern continued into index year 2016 with $66.7 \%$ of all patients receiving lenvatinib in LOT1. Lenvatinib was also the most common regimen in LOT2 during the 2015 index year (45.5\% of all patients). 


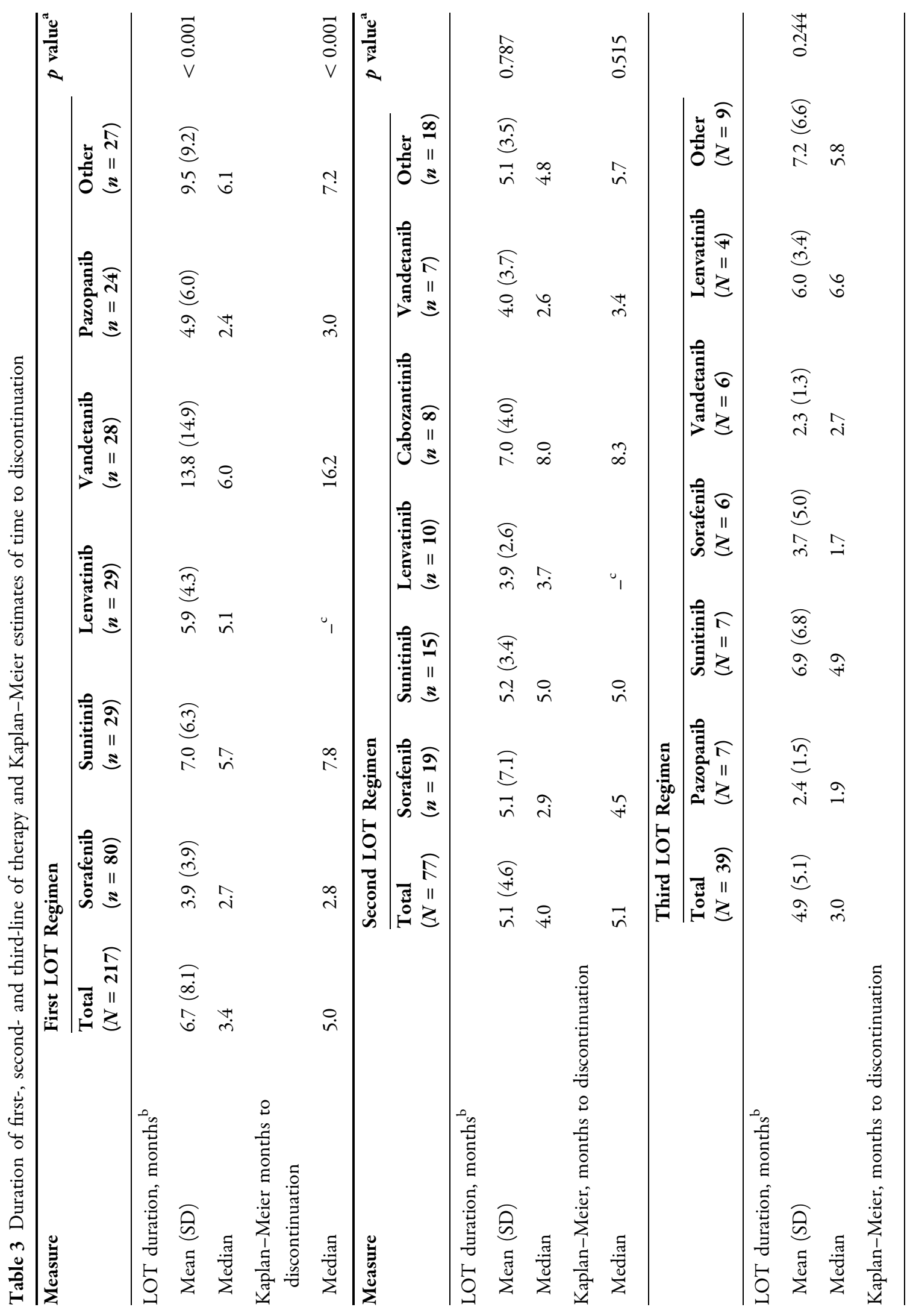




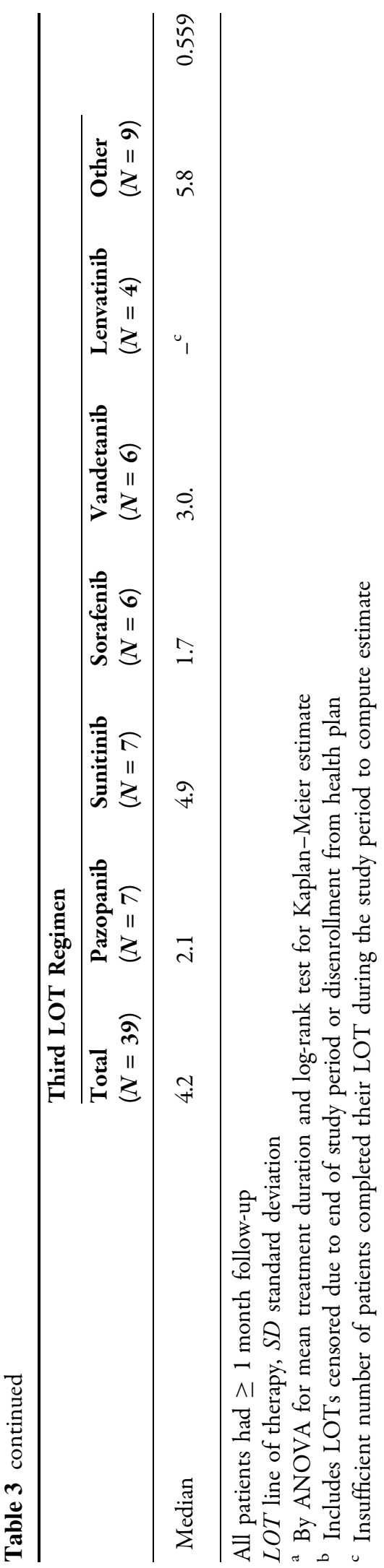

\section{SMKI Treatment Duration and Treatment Sequence Patterns}

Among all regimens, mean (median) treatment duration was 6.7 months (3.4 months) for LOT1, 5.1 months (4.0 months) for LOT2 and 4.9 months (3.0 months) for LOT3 (Table 3). Kaplan-Meier estimates of median time to treatment discontinuation showed a similar pattern: LOT1, 5.0 months; LOT2, 5.1 months; LOT3, 4.2 months. Mean LOT1 duration differed between cohorts: sorafenib had the shortest mean duration (3.9 months) and vandetanib had the longest duration (13.8 months) $(p<0.001)$. Kaplan-Meier estimates of median time to treatment discontinuation in LOT1 were also the shortest for sorafenib (2.8 months) and the longest for vandetanib (16.2 months) $(\mathrm{P}<0.001)$. The lenvatinib cohort had the shortest follow-up time among all regimens and the number of patients with complete LOT data was insufficient to compute Kaplan-Meier median estimates for this cohort in any LOT. In LOT2, mean duration ranged from 3.9 months (lenvatinib) to 7.0 months (cabozantinib) but did not differ between LOT2 cohorts $(p=0.787)$. The pattern was similar for Kaplan-Meier median estimates, ranging from 3.4 months (vandetanib) to 8.3 months (cabozantinib) $(p=0.515)$. The mean duration of LOT3 was lowest for the vandetanib cohort (2.3 months) and highest for "other" regimens (7.2 months) but did not differ between regimens $(p=0.244)$. Kaplan-Meier median estimates were also similar between cohorts $(p=0.559)$, varying from 1.7 months (sorafenib) to 5.8 months ("other" regimens).

Treatment sequence patterns during the transition from LOT1 to LOT2 and from LOT2 to LOT3 are shown in Fig. 5. It was common for patients to receive similar regimens from LOT1 to LOT2; the same pattern was evident but to a lesser extent for the transition from LOT2 to LOT3. The proportion of patients in LOT2 who received the same regimen in LOT1 varied from $0 \%$ (cabozantinib) to $84.2 \%$ (sorafenib). Of the 77 patients receiving LOT2, 33 $(42.9 \%)$ had received sorafenib in LOT1. The percentage of patients with the same regimen 
Panel A. Second LOT regimens received stratified by first LOT regimens

${ }^{a}$ All patients had $\geq 1$ month follow-up

LOT, line of therapy

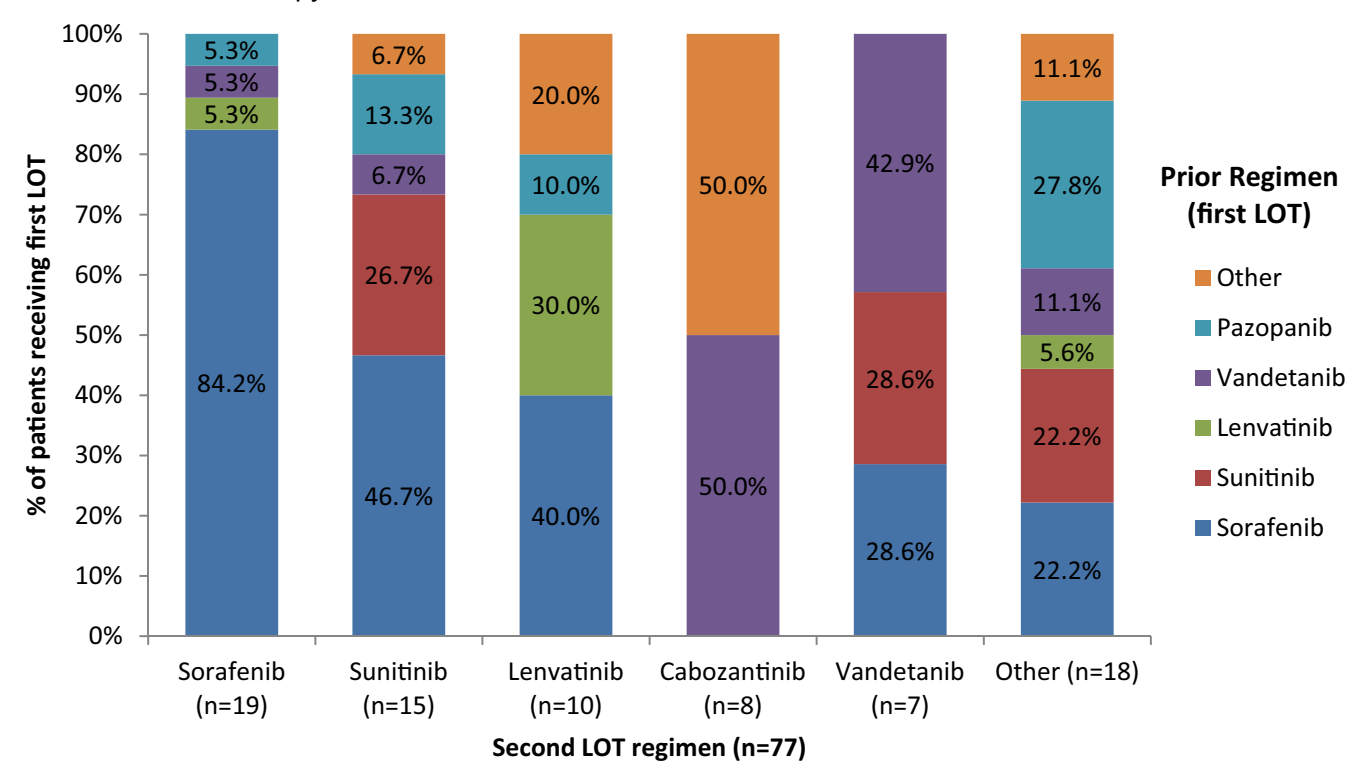

Panel B. Third LOT regimens received stratified by second LOT regimens

${ }^{\text {a }}$ All patients had $\geq 1$ month follow-up

LOT, line of therapy

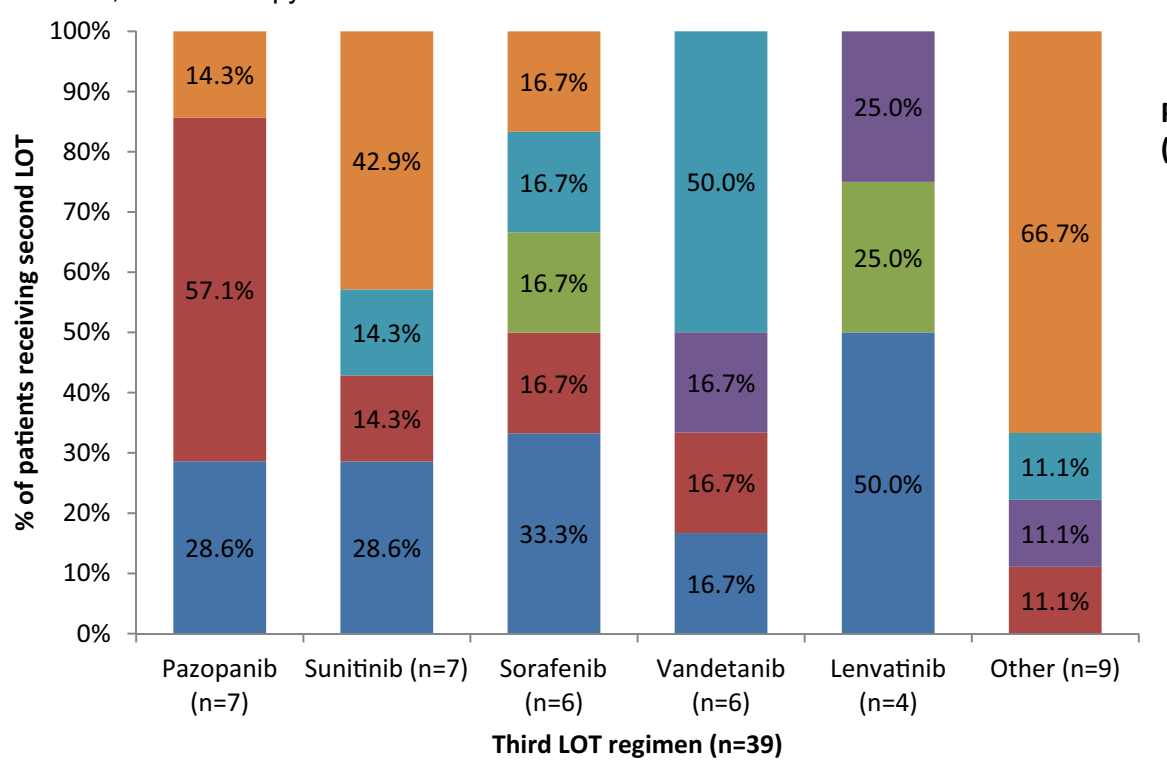

Prior Regimen (second LOT)

n Other

- Pazopanib

- Vandetanib

- Lenvatinib

- Sunitinib

- Sorafenib

Fig. 5 SMKI regimen sequence ${ }^{a}$

in LOT2 and LOT3 ranged from $0.0 \%$ (pazopanib) to $33.3 \%$ (sorafenib). Of the 39 patients receiving LOT3, the most common LOT2 regimen was also sorafenib $(n=9$, $23.1 \%)$.

\section{DISCUSSION}

Multiple SMKI therapies are currently available for patients with advanced thyroid cancer [9]. Our results suggest that SMKI treatments 
patterns have changed since the introduction of lenvatinib in 2015. Over the entire study period (2010-2016), sorafenib was the predominant regimen in both the first-line $(36.9 \%$ of all patients) and second-line setting (24.7\%). Among patients starting SMKI therapy in 2015 and later, lenvatinib became the most common first-line regimen: $43.4 \%$ of patients in 2015 and $66.7 \%$ of patients in 2016 received lenvatinib in the first line of therapy. Lenvatinib was also the most common second-line regimen among patients initiating therapy in 2015 .

The large majority of SMKI regimens were single agents which is consistent with previous retrospective analyses $[22,23]$. Our results also show frequent use of agents that are NCCNrecommended but not approved by FDA for advanced DTC and MTC; sunitinib was often used in all lines of therapy and pazopanib was a common first-line regimen. Patients were observed on average for 16.6 months after initiation of the first line of therapy but duration of follow-up varied considerably between SMKI regimens. Patients receiving lenvatinib in firstline therapy had the shortest mean duration of follow-up time (8.3 months) while patients treated with vandetanib in the first-line setting averaged the longest duration of follow-up (22.9 months). This pattern likely coincides with the timing of FDA approval of agents for advanced thyroid cancer relative to the end date for inclusion in the study (May 2016): lenvatinib was the last drug to approved by FDA (2015, for DTC) while vandetanib received the earliest approval (2011, for MTC). The remaining single agent regimens either received FDA approval for advanced thyroid cancer by 2013 (cabozantinib for MTC and sorafenib for DTC) or were available for other indications before the study start date (pazopanib, sorafenib and sunitinib).

We examined time to treatment discontinuation of each SMKI regimen in first-, secondand third-line therapy as a proxy for clinical benefit as cancer treatments are typically discontinued when they are no longer effective or tolerable. Treatment duration is a composite measure that does not distinguish between efficacy, tolerability and other causes of therapy discontinuation. However, it is a commonly reported metric in clinical trials and often a key outcome in observational studies of oncology treatments [30-33]. Kaplan-Meier estimates of median time to discontinuation differed significantly by regimen in the first line of therapy: sorafenib had the shortest estimate (2.8 months) and vandetanib had the longest estimate (16.2 months). No significant differences between regimens were observed in subsequent lines of therapy. Overall, estimates of treatment duration in the first and later lines of therapy were lower than observed in clinical trials $[24,34,35]$. This likely reflects differences in the profile of patients and patient management between clinical practice vs. the controlled environment of clinical trials. Moreover, large inter-patient variability in SMKI treatment duration has been observed outside the clinical trial setting [21]. The side effect profile of SMKI regimens may also have influenced treatment duration [36]. Sorafenib use has been associated with occasional lack of tolerability, necessitating dose reductions/re-escalation, drug interruptions/re-start and withdrawal (particularly in early treatment cycles) [20, 21, 37] while vandetanib is generally better tolerated than sorafenib [36]. In addition, comorbid conditions may have impacted treatment duration or warranted dose reductions. It is also possible that the pharmacy claims-based algorithm used to define lines of therapy and duration of therapy in this study $[28,29]$ underestimated duration of therapy because dose reductions or drug interruptions were not observable in this analysis. The definition of each line of therapy considered medication fills and timing of the refills. If a 60-day or greater gap in medication supply occurred prior to the initiation of a new agent, the gap signaled the end of a line of therapy. However, a $50 \%$ dose reduction in a 60 -day prescription could cause a 60-day delay in the next prescription refill and result in misclassifying a patient as ending that line of therapy.

Patients receiving sorafenib, sunitinib, lenvatinib or vandetanib as first-line therapy commonly received the same regimen in the second line of therapy. A similar pattern was evident in the third-line setting but to a lesser degree. This finding was unexpected given the 
availability of several SMKI for use in this population [9]. Sequential use of the same therapy may also reflect a drug holiday to allow patients to recover from side effects followed by a rechallenge, or, as noted above, a dose reduction. Alternatively, patients may have been re-challenged with the same drug for reasons other than side effects. For example, a patient may have started therapy and subsequently stopped if there was no evidence of disease progression but later re-started the same therapy after disease progression occurred. Use of second and later lines of therapy was generally modest. Among the subset of patients with ample follow-up time (which produced the largest estimates), only $53.7 \%$ of patients received a second or later line of therapy. This is consistent with the rate of $49 \%$ observed in a previous study examining multiple first-line SMKIs in advanced DTC and MTC [23]. The results of recent retrospective studies support clinical benefit of SMKI in the second-line setting $[20,22,23]$. In a French study of patients treated with sunitinib or sorafenib, median progression-free survival was similar in both the firstline (7.0 months) and second-line setting (6.7 months) [22]. Owonikoko et al. also observed clinical benefit of second-line therapy in a US study examining several first- and second-line SMKI therapies; however efficacy diminished in the second-line vs. first-line setting (median progression-free survival 4.6 months vs. 16.2 months) [23]. In addition, the results of a phase 3 clinical trial of lenvatinib showed relatively similar median progression-free survival among patients who had received no prior tyrosine kinase inhibitor therapy (18.7 months) and among patients treated with one previous tyrosine kinase inhibitor regimen (15.1 months) [24]. Our results also suggest benefit of SMKI in the second-line setting: among all patients, median times to treatment discontinuation were 5.0 months in first-line vs. 5.1 months in second-line treatment. However, it is important to note that our estimates of treatment duration for the secondline setting represented $35.4 \%$ of the patients with first-line therapy and should not be interpreted to suggest similar efficacy of SMKI in first- and second-line setting. Further, there were insufficient data to identify specific treatment sequencing to substantiate benefit in the second-line setting.

To our knowledge, this is the first study to examine real-world SMKI treatment patterns since the approval of lenvatinib, in 2015. The primary strength of this study is that the patient sample, drawn from a large, national commercial insurance database, was considerably larger than previous studies and had broader geographic representation [20-23]. The demographics of our study sample (mean age: 61.2 years; $51.6 \%$ female) are consistent with patients undergoing SMKI treatment in recent clinical trials (median age 63-64 years; $48-50 \%$ female [24, 38]). Our results suggest that, at most, only a slight majority of patients receive a second or later line of SMKI therapy in realworld clinical practice. Future research should examine the impact of treatment sequencing on clinical outcomes. While our study lends support to previous research suggesting clinical benefit in the second-line setting [20, 22, 23], future research is needed to establish consensus for the optimal choice of SMKI in second and later lines of therapy. Assessment of patient characteristics that are predictive of clinical outcomes in second and later lines of therapy is also needed to identify patients who would benefit from SMKI therapy after progression on first-line therapy. In addition, the availability of SMKI regimens for use in routine clinical practice is still relatively recent, particularly for lenvatinib. Thus, some patients may already have experienced significant disease progression prior to SMKI treatment. Future studies are needed to build on our findings as the use of SKMI regimens becomes further established in the general population.

The results of our study are limited by its retrospective nature. In particular, our results are based on data from an administrative claims database and have limitations typical not only of claims-based research in general but also the specific disease state examined. First, claims data are collected for reimbursement, not research, and may be subject to miscoding and errors of omission. Any errors or inconsistencies in the documentation of codes for diagnoses or medications may lead to misclassification of 
patients into regimen cohorts. However, the rate of these errors is expected to be low because of the comprehensive documentation of codes required for reimbursement. Furthermore, we would not expect any systematic differences in the occurrence of errors between the cohorts of interest. Secondly, claims data lack certain clinical information (e.g., tumor staging, histology, disease progression, radioiodine refractory status, prescribing patterns) that may be relevant to the treatment patterns observed in this study. For example, ICD-9-CM and ICD-10$\mathrm{CM}$ diagnosis codes were used to identify patients with thyroid cancer; however, these codes do not distinguish DTC from MTC or other forms of primary thyroid cancer which may have influenced SMKI treatment regimen. Thirdly, treatment patterns were identified based on pharmacy claims for SMKI. However, pharmacy claims do not indicate if the patient took the medication at all or as prescribed. Fourth, we used an established prescription claims-based algorithm to identify distinct lines of therapy [28, 29]. This included treatment gaps of 60 days or more (based on days' supply of therapy) to demark the end of a line of therapy. However, the initiation of a new line of therapy due to disease progression after a 60-day or greater break in therapy is indistinguishable from restarting the same regimen after a drug interruption or a lengthy dose reduction. Fifth, we used time to treatment discontinuation as a proxy for clinical benefit in each line of therapy; however, our database lacked clinically-based measures of efficacy (e.g., survival, Response Evaluation Criteria In Solid Tumors [RECIST] response rates, side effects, rationale for therapy discontinuation). Further, the observation window for lenvatinib was brief (2015-2016), resulting in an insufficient number of patients to estimate treatment duration for any line of therapy in this cohort. Sixth, claims databases may not capture complete information for patients who participated in clinical trials during the course of the study. Nevertheless, our objective was to examine realworld use of SMKI and the literature suggests that less than $5 \%$ of oncology patients enroll in clinical trials [39, 40]. Seventh, although the overall study sample was considerably larger than previous studies of SMKI treatment patterns [20-23], the sample sizes in the subgroup analysis of SMKI regimen by LOT were relatively small which is associated with low statistical power. Finally, the results are based on a sample of patients with commercial or Medicare Advantage insurance and may not be generalizable to patients with other forms of insurance or the uninsured.

\section{CONCLUSIONS}

SMKI treatment patterns appeared to change over the course of the study. During the full study period (2010-2016), sorafenib was the most common regimen in the first- and secondline setting. Following FDA approval in 2015, lenvatinib was the predominant regimen in the first and second lines of therapy. Approximately $36-53 \%$ of patients received a second or later line of therapy. Median time to treatment discontinuation was similar for first and second lines of therapy, suggesting that SMKI treatment may be considered after first-line failure in appropriately selected patients although additional research is needed to identify optimal treatment sequencing.

\section{ACKNOWLEDGEMENTS}

Funding. Eisai, Inc. (Woodcliff Lake, NJ) sponsored this study and also funded the open access fees and article processing charges associated with the publication of this article. All authors had full access to all of the data in this study and take complete responsibility for the integrity of the data and accuracy of the data analysis.

Medical Writing and Other Assistance. The authors thank Mary DuCharme and Damon Van Voorhis (Optum, Inc.) for programming support. Sarah Peirce-Sandner provided medical writing assistance and was funded by Eisai.

Authorship. All named authors meet the International Committee of Medical Journal 
Editors (ICMJE) criteria for authorship for this manuscript, take responsibility for the integrity of the work as a whole, and have given final approval for the version to be published.

Prior Presentation. A portion of the results of this study were previously published as an abstract only without presentation: J Clin Oncol 35, 2017 (suppl; abstr e17589).

Disclosures. Stacey Dacosta-Byfield is an employee of Optum, Inc. which was contracted by Eisai to conduct the study. Oluwakayode Adejoro was an employee of Optum at the time of the study and was an employee of Eisai during manuscript development. Debanjana Chatterjee is an employee of Eisai. Prashant Ramesh Joshi is an employee of Eisai. Ronda Copher was an employee of Eisai at the time of the study. Francis P. Worden has received research funding from Eisai Inc. and Bayer HealthCare Pharmaceuticals.

Compliance with Ethics Guidelines. Because no identifiable protected health information was extracted or accessed during the course of the study, and all data were accessed in compliance with the Health Insurance Portability and Accountability Act's rules, Institutional Review Board approval or waiver of authorization was not required.

Data Availability. The data contained in our database contains proprietary elements owned by Optum and, therefore, cannot be broadly disclosed or made publicly available at this time. The disclosure of this data to thirdparty clients assumes certain data security and privacy protocols are in place and that the third party client has executed our standard license agreement which includes restrictive covenants governing the use of the data.

Open Access. This article is distributed under the terms of the Creative Commons Attribution-NonCommercial 4.0 International License (http://creativecommons.org/licenses/ by-nc/4.0/), which permits any noncommercial use, distribution, and reproduction in any medium, provided you give appropriate credit to the original author(s) and the source, provide a link to the Creative Commons license, and indicate if changes were made.

\section{REFERENCES}

1. Rahib L, Smith BD, Aizenberg R, Rosenzweig AB, Fleshman JM, Matrisian LM. Projecting cancer incidence and deaths to 2030: the unexpected burden of thyroid, liver, and pancreas cancers in the United States. Cancer Res. 2014;74(11): 2913-21.

2. American Cancer Society. Cancer facts \& figures 2018. https://www.cancer.org/content/dam/ cancer-org/research/cancer-facts-and-statistics/annu al-cancer-facts-and-figures/2018/cancer-facts-andfigures-2018.pdf. Accessed 29 Oct 2018.

3. Siegel RL, Miller KD, Jemal A. Cancer Statistics, 2017. CA Cancer J Clin. 2017;67(1):7-30.

4. Sosa JA, Hanna JW, Robinson KA, Lanman RB. Increases in thyroid nodule fine-needle aspirations, operations, and diagnoses of thyroid cancer in the United States. Surgery. 2013;154(6):1420-6 (discussion 26-7).

5. Lim H, Devesa SS, Sosa JA, Check D, Kitahara CM. Trends in thyroid cancer incidence and mortality in the United States, 1974-2013. JAMA. 2017;317(13):1338-48.

6. Howlader N, Noone A, Krapcho M, et al. SEER cancer statistics review, 1975-2014, National Cancer Institute. Bethesda, MD, based on November 2016 SEER data submission, posted to the SEER web site, April 2017. https://seer.cancer.gov/csr/1975 2014/sections.html. Accessed 29 Oct 2018.

7. Are C, Shaha AR. Anaplastic thyroid carcinoma: biology, pathogenesis, prognostic factors, and treatment approaches. Ann Surg Oncol. 2006;13(4):453-64.

8. Anderson RT, Linnehan JE, Tongbram V, Keating K, Wirth LJ. Clinical, safety, and economic evidence in radioactive iodine-refractory differentiated thyroid cancer: a systematic literature review. Thyroid. 2013;23(4):392-407.

9. National Comprehensive Cancer Network. NCCN clinical practice guidelines in oncology (NCCN guidelines). Thyroid carcinoma. v.2.2017-May 17, 2017 https://www.nccn.org/professionals/physician_ gls/f_guidelines.asp. Accessed 20 Nov 2017. 
10. Durante C, Haddy N, Baudin E, et al. Long-term outcome of 444 patients with distant metastases from papillary and follicular thyroid carcinoma: benefits and limits of radioiodine therapy. J Clin Endocrinol Metab. 2006;91(8):2892-9.

11. Roman S, Lin R, Sosa JA. Prognosis of medullary thyroid carcinoma: demographic, clinical, and pathologic predictors of survival in 1252 cases. Cancer. 2006;107(9):2134-42.

12. Robbins RJ, Wan Q, Grewal RK, et al. Real-time prognosis for metastatic thyroid carcinoma based on 2-[18F]fluoro-2-deoxy-D-glucose-positron emission tomography scanning. J Clin Endocrinol Metab. 2006;91(2):498-505.

13. Cabanillas ME, Habra MA. Lenvatinib: role in thyroid cancer and other solid tumors. Cancer Treat Rev. 2016;42:47-55.

14. O’Neill CJ, Oucharek J, Learoyd D, Sidhu SB. Standard and emerging therapies for metastatic differentiated thyroid cancer. Oncologist. 2010;15(2): 146-56.

15. Haugen BR, Alexander EK, Bible KC, et al. 2015 American Thyroid Association Management guidelines for adult patients with thyroid nodules and differentiated thyroid cancer: The American Thyroid Association Guidelines Task Force on Thyroid Nodules and Differentiated Thyroid Cancer. Thyroid. 2016;26(1):1-133.

16. Nexavar (sorafenib) tablets [prescribing information]. Whippany, NJ: Bayer HealthCare Pharmaceuticals, Inc; 2017. http://labeling.bayerhealth care.com/html/products/pi/Nexavar_PI.pdf. Accessed 29 Oct 2018.

17. Lenvima (lenvatinib) capsules [prescribing information]. Woodcliff Lake, NJ: Eisai Inc; 2018. http:// www.lenvima.com/pdfs/prescribing-information. pdf. Accessed 29 Oct 2018.

18. Caprelsa (vandetanib) tablets [prescribing information]. Cambridge, MA: Genzyme Corporation; 2016. http://www.caprelsarems.com/files/caprelsapi.pdf?v=2.0. Accessed 29 Oct 2018.

19. Cometriq (cabozantinib) capsules [prescribing information]. South San Franciso, CA: Exelixis Inc; 2016. https://cometriq.com/downloads/Cometriq_ Full_Prescribing_Information.pdf. Accessed 29 Oct 2018.

20. Dadu R, Devine C, Hernandez M, et al. Role of salvage targeted therapy in differentiated thyroid cancer patients who failed first-line sorafenib. J Clin Endocrinol Metab. 2014;99(6):2086-94.
21. Chrisoulidou A, Mandanas S, Margaritidou E, et al. Treatment compliance and severe adverse events limit the use of tyrosine kinase inhibitors in refractory thyroid cancer. Onco Targets Ther. 2015;8:2435-42.

22. Massicotte $\mathrm{MH}$, Brassard $\mathrm{M}$, Claude-Desroches $\mathrm{M}$, et al. Tyrosine kinase inhibitor treatments in patients with metastatic thyroid carcinomas: a retrospective study of the TUTHYREF network. Eur J Endocrinol. 2014;170(4):575-82.

23. Owonikoko TK, Chowdry RP, Chen Z, et al. Clinical efficacy of targeted biologic agents as second-line therapy of advanced thyroid cancer. Oncologist. 2013;18(12):1262-9.

24. Schlumberger M, Tahara M, Wirth LJ, et al. Lenvatinib versus placebo in radioiodine-refractory thyroid cancer. N Engl J Med. 2015;372(7):621-30.

25. Smith JC, Medalia C. U.S Census Bureau, current population reports, P60-253. Health Insurance Coverage in the United States: 2014 https://www. census.gov/content/dam/Census/library/publicati ons/2015/demo/p60-253.pdf. Accessed 11 Apr 2018.

26. Quan H, Li B, Couris CM, et al. Updating and validating the Charlson comorbidity index and score for risk adjustment in hospital discharge abstracts using data from 6 countries. Am J Epidemiol. 2011;173(6):676-82.

27. Agency for Healthcare Research and Quality. Clinical classification software (CCS) for ICD-9-CM. https://www.hcup-us.ahrq.gov/toolssoftware/ccs/ ccs.jsp. Accessed 17 Dec 2018.

28. Burton T, Byfield SD, Smith GL, et al. Clinical and economic outcomes by first-line treatment among women with $\mathrm{HR}+/$ HER 2 - metastatic breast cancer in a large US health plan database. Curr Med Res Opin. 2016;32(8):1417-23.

29. Seal B, Chastek B, Kulakodlu M, Valluri S. Differences in survival for patients with metastatic colorectal cancer by lines of treatment received and stage at original diagnosis. Int $\mathrm{J}$ Clin Pract. 2015;69(2):251-8.

30. Macalalad AR, Hao Y, Lin PL, et al. Treatment patterns and duration in post-menopausal women with HR+/HER 2 - metastatic breast cancer in the US: a retrospective chart review in community oncology practices (2004-2010). Curr Med Res Opin. 2015;31(2):263-73.

31. McKay C, Burke T, Cao X, Abernethy AP, Carbone DP. Treatment patterns for advanced non-small-cell lung cancer after platinum-containing therapy in 
U.S. community oncology clinical practice. Clin Lung Cancer. 2016;17(5):449-60.

32. Pilon D, Behl AS, Ellis LA, Emond B, Lefebvre P, Dawson NA. Duration of treatment in prostate cancer patients treated with abiraterone acetate or enzalutamide. J Manag Care Spec Pharm. 2017;23(2):225-35.

33. Schultz NM, Flanders SC, Wilson S, et al. Treatment duration, healthcare resource utilization, and costs among chemotherapy-naive patients with metastatic castration-resistant prostate cancer treated with enzalutamide or abiraterone acetate: a retrospective claims analysis. Adv Ther. 2018;35(10):1639-55.

34. Gupta-Abramson V, Troxel AB, Nellore A, et al. Phase II trial of sorafenib in advanced thyroid cancer. J Clin Oncol. 2008;26(29):4714-9.

35. Wells SA Jr, Robinson BG, Gagel RF, et al. Vandetanib in patients with locally advanced or metastatic medullary thyroid cancer: a randomized, doubleblind phase III trial. J Clin Oncol. 2012;30(2):134-41.

36. Klein Hesselink EN, Steenvoorden D, Kapiteijn E, et al. Therapy of endocrine disease: response and toxicity of small-molecule tyrosine kinase inhibitors in patients with thyroid carcinoma: a systematic review and meta-analysis. Eur J Endocrinol. 2015;172(5):R215-25.

37. Worden F, Fassnacht M, Shi Y, et al. Safety and tolerability of sorafenib in patients with radioiodine-refractory thyroid cancer. Endocr Relat Cancer. 2015;22(6):877-87.

38. Brose MS, Nutting CM, Jarzab B, et al. Sorafenib in radioactive iodine-refractory, locally advanced or metastatic differentiated thyroid cancer: a randomised, double-blind, phase 3 trial. Lancet. 2014;384(9940):319-28.

39. Al-Refaie WB, Vickers SM, Zhong W, Parsons H, Rothenberger D, Habermann EB. Cancer trials versus the real world in the United States. Ann Surg. 2011;254(3):438-42 (discussion 42-3).

40. Murthy VH, Krumholz HM, Gross CP. Participation in cancer clinical trials: race-, sex-, and age-based disparities. JAMA. 2004;291(22):2720-6. 